\title{
Derechos humanos y el derecho a un ambiente sano
}

Human rights and the right to a healthy environment

\author{
Eduardo Arturo Kerguelén Durango ${ }^{1}$ \\ Universidad de Córdoba, Montería, Colombia
}

Recibido el 7 de junio de 2017, aceptado el 2 de agosto de 2017

Disponible en internet el 12 de agosto de 2017

\begin{abstract}
Resumen: En este artículo se pretende realizar un análisis de reflexión sobre la relación existente entre el derecho a un ambiente sano y los derechos humanos universales, tratando de incorporar su evolución y trascendencia histórica en los ámbitos social, político y económico. El ambiente sano es un derecho Constitucional fundamental, pues su violación atenta directamente contra la especie humana y, en consecuencia, con los derechos más fundamentales del hombre. La segunda parte, contempla el desarrollo económico frente al medio ambiente y la inminente necesidad de trazar políticas económico-ambientales, es decir aquellas políticas inclinadas a la defensa de lo ambiental sin que se frene el desarrollo industrial que permite mejorar la calidad de vida
\end{abstract}

Palabras claves: Ambiente sano, derechos humanos, derecho fundamental.

\section{INTRODUCCIÓN}

La presente investigación está referida al tema de los derechos humanos y el derecho a un ambiente sano, que se podrían definir, en el primer caso, como aquellos que según Lobo (1999) presentan características esenciales como ser inalienables, imprescriptibles e irrenunciables, por lo que podría decirse que tanto los derechos humanos, como los civiles, a la libertad, individuales y las libertades públicas, son formas diferentes de expresar una misma realidad integrante del concepto de ciudadanía. Por su parte, el derecho a un ambiente sano, es considerado como uno de los derechos que hacen parte de la tercera generación de derechos, que se concreta en una doble exigencia para los poderes públicos: abstención de dañar el objeto del derecho y obligación de protegerlo. Este derecho, se proyecta, de acuerdo con Jaume y Jaria (2016), en los derechos individuales, pues es derecho de cada individuo el goce de un ambiente sano, pero a su vez se le añade el deber de protegerlo ya que tiene igualmente un carácter colectivo y solidario.

\footnotetext{
${ }^{1}$ Correo electrónico: ekerguelen@ correo.unicordoba.edu.co
} 
En tal sentido, es dable sugerir que los titulares de los derechos humanos son todos los hombres que por el sólo hecho de serlo pueden invocarlos, con independencia de circunstancias de sexo, raza, credo religioso o político, status social, económico o cultural; mientras que los derechos colectivos, también llamados derechos del pueblo o de solidaridad, están basados en los valores sociales emergentes en una sociedad tecnificada y que se refieren a una unión entre los de primera y segunda generación, como lo es el derecho a la autodeterminación, a la independencia económica, a la identidad cultural y la paz. Implican un cambio de paradigma en su protección, siendo considerados los derechos propios de la modernidad (Londoño, 2006).

Este artículo de reflexión se realizó por el interés de ahondar un poco más sobre el conocimiento acerca de la relación existente entre el derecho a un ambiente sano y los derechos humanos universales, procurando incorporar su evolución y trascendencia histórica en los ámbitos social, político y económico. Así mismo, profundizar acerca de este tema, fue un interés académico desde el campo del derecho.

Esta investigación se realizó a través de una revisión documental, entrevistas con algunos profesionales del derecho y docentes con cierto dominio sobre el tema, en el marco de la noción sobre los derechos humanos y el derecho a un ambiente sano. El objeto fue analizar la relación existente entre el derecho a un ambiente sano y los derechos humanos universales.

\section{NOCIONES SOBRE DERECHOS HUMANOS}

Se puede considerar al derecho natural como aquel conjunto de valores y principios que no necesariamente deben estar expresos en la codificación normativa diseñadas por la sociedad, y que cualquier individuo puede apelarlos en cualquier momento, estén o no visibles en términos de derecho positivo, siendo exigibles aun cuando un derecho positivo concreto los refute (Hervada, 1986). Ahora bien, Finnis (2000) considera que los derechos humanos o naturales son los derechos morales fundamentales y generales, derivados de las formas generales de derechos morales, de los derechos humanos, cuya distinción así trazada por el uso no es muy clara. Es por ello que Altamirano (2003) considera a los derechos humanos como verdaderos derechos naturales. 
Una de las características esenciales de los derechos fundamentales es ser inalienables, imprescriptibles e irrenunciables, por lo que podría decirse que tanto los derechos humanos, como los civiles, a la libertad, individuales, las libertades públicas, son formas diferentes de expresar una misma realidad integrante del concepto de ciudadanía, consolidados desde los inicios del liberalismo (Lobo, 1999). En tal sentido, es dable sugerir que los titulares de los derechos humanos son todos los hombres, por el sólo hecho de serlo pueden invocarlos, con independencia de circunstancias de sexo, raza, credo religioso o político, status social, económico o cultural, etc., entre otros.

La fundamentación de los derechos humanos está intrínsecamente conectada con ciertas características definitorias del discurso o razonamiento moral en el que deben ser cimentados, por lo que encuentra su soporte en tres principios fundamentales: la inviolabilidad, la autonomía y la dignidad humana (Altamirano, 2003). En términos generales, los derechos humanos pueden definirse como aquellos derechos inherentes a la naturaleza humana, sin los que no podríamos vivir como seres humanos.

De acuerdo con Jiménez (1999), los derechos humanos pueden ser considerados como un derecho creado por la Constitución exigiendo al ordenamiento jurídico una determinación hermenéutica y una construcción dogmática porque los tribunales deberían identificar qué cosa es un derecho fundamental y cual no; mientras que Ferrajoli (2001) considera que los derechos fundamentales son todos aquellos derechos subjetivos que las normas de un determinado ordenamiento jurídico atribuyen universalmente a todos en tanto personas, ciudadanos y/o personas capaces de obrar.

Mesa (2008), sostiene que los derechos humanos deben ser planteados con una visión de integralidad, la cual establece el reconocimiento de los tres principales momentos de la historia de los derechos humanos - conocida ampliamente en la doctrina de los derechos humanos como generaciones de derechos-: desde los derechos civiles y políticos (siglos XVII y XIX), pasando por los derechos sociales, económicos y culturales (siglo XIX y XX). Sostiene Jaume y Jaria (2016) que éstos últimos poseen, en sí mismos, una dimensión pública y una dimensión colectiva en la que se desarrollan a plenitud, caracterizándose por requerir cierta actividad del Estado ya sea de alguna prestación de servicio -como el 
derecho a la salud o a la educación- o bien de la limitación de los derechos de la libertad por alguna oposición al bien común.

Finalmente, encontramos los derechos de tercera generación (siglos XX y XXI), también llamados derechos del pueblo o de solidaridad, los cuales están basados en los valores sociales emergentes en una sociedad tecnificada. Estos derechos se refieren a una unión entre los de primera y segunda generación, como lo es el derecho a la autodeterminación, a la independencia económica, a la identidad cultural y la paz. En esta clasificación encontramos el derecho a un ambiente sano que se concreta en una doble exigencia para los poderes públicos: abstención de dañar el objeto del derecho y obligación de protegerlo. Así mismo, se proyecta en los derechos individuales, pues es derecho de cada individuo el goce de un ambiente sano, pero a su vez se le añade el deber de protegerlo ya que tiene igualmente un carácter colectivo y solidario (Jaume y Jaria, 2016).

De esta manera entonces, los derechos colectivos constituyen una nueva generación de derechos, los cuales surgen frente a necesidades sociales colectivas y su reconocimiento se inicia a través de instrumentos internacionales. Implican un cambio de paradigma en su protección, siendo considerados los derechos propios de la modernidad (Londoño, 2006).

Según la Conferencia de Estocolmo (1972), no hay un claro consenso sobre si en verdad el derecho ambiental surge ante la creciente preocupación mundial por los problemas ambientales o por el contrario es una rama cuyos orígenes se remontan al siglo XIX o mucho antes. Algunos autores señalan que el derecho ambiental ha surgido como respuesta a los graves problemas ambientales y coinciden con la Declaración de la Conferencia de las Naciones Unidas sobre el Medio Ambiente Humano. Para Sánchez (2012) no existe claridad sobre el surgimiento de este derecho, tomando en consideración al derecho ambiental como un sistema de normas, instituciones, prácticas e ideologías jurídicas eventualmente útiles para la tutela del equilibrio de los ecosistemas.

Desde la Cumbre de Estocolmo de 1972, el hombre ha sido considerado obra y artífice de su entorno, lo que le da el sustento material y le brinda la oportunidad de desarrollarse intelectual, moral, social y espiritualmente, lo cual indica que la naturaleza está al servicio del hombre, quien debe garantizar la estabilidad de las generaciones futuras. Así mismo, en esta cumbre se estableció que el hombre tiene derecho fundamental a la libertad, la 
igualdad y adecuadas condiciones de vida, en un medio ambiente de una calidad que permita una vida de dignidad y bienestar.

Ibáñez (1988) considera la existencia de un límite entre la ecología -entendida como el noble y positivo afán del amor por la naturaleza y la preocupación por el futuro del hombre- con una suerte de ideología difusa fundada en axiomas doctrinales naturalistas y materialistas -lo que aduce podrían comprenderse bajo el signo de ecologismo-. El autor, asiente que la ecología reúne disciplinas muy diversas, tanto de las ciencias de la naturaleza como de las ciencias humanas, en torno a una preocupación fundamental por la labor destructiva del hombre sobre la naturaleza y, al contrario, por la necesidad de preservarla como medio ambiente y como fuente de recursos. Estas tendencias ecologistas tienen por común denominador una visión dramática del futuro del mundo, colocando a la naturaleza en un plano, por poco, superior al hombre lo cual es inaceptable desde el punto de vista axiológico.

Al respecto, la Corte Constitucional en sentencia T-092 de 1993 sostuvo:

(...) también incuestionable que el Estado y sus instituciones están obligadas a planificar, organizar, coordinar y controlar el uso de los recursos naturales e igualmente brindar dentro de lo posible, un medio ambiente sano, para que tanto la naturaleza y con mayor énfasis el hombre, puedan gozar a plenitud de la existencia. Por esa justa razón cuando se trate de realizar obras como las que se está cuestionando, el Estado tiene la imperiosa obligación de realizar los estudios científicos del caso para evitar que a través de la infraestructura que se proyecta, en vez de beneficios se le cause perjuicios a la comunidad (sentencia T-092/93)

Hervada (1986), asegura que el derecho a gozar de un ambiente sano configura la existencia de un derecho humano digno de tutela y no de un derecho del ambiente; derecho alude al sistema racional de relaciones; es decir, supone un conjunto de vínculos estructurados por sujetos libres y responsables por lo que resulta injustificado referirse a derecho del ambiente. Este derecho humano constituye un derecho al ambiente sano pues sin éste el hombre no podría alcanzar su perfeccionamiento.

En tal sentido, Rabbi (1996) sostiene que no se trata solo de vivir sino que hemos de procurar alcanzar lo que ya Aristóteles (Política, 1252 a 1-3 b 27-1253 a 1) conocía como la "vida buena". Es entonces cuando se considera que el derecho ambiental incumbe un deber 
-impuesto por el carácter sagrado y trascendente de la persona- en cabeza de la sociedad de respetar el medio ambiente, el cual implica que no sólo es un deber presente sino también futuro. Dicho en otras palabras, las relaciones jurídicas que tengan por objeto la protección al medio ambiente deberán asumir una disposición de perpetuidad. Como quiera que los derechos humanos se reputan inalienables, también habrá de serlo el ambiente en el que actúan. A ello, precisamente, hace referencia la noción de "derecho de las futuras generaciones", en cuanto nos plantea que el mismo ecosistema no es patrimonio de una generación sino por el contrario “patrimonio común” de todas Rabbi (1996).

Las principales preocupaciones del derecho a un ambiente sano apuntan al logro de un desarrollo sostenible el cual pretende evitar la destrucción del ambiente y respetar la soberanía de todos los Estados que depende de la puesta en marcha de diversas estrategias políticas y económicas. Los nuevos derechos están orientados a un redescubrimiento de la noción de bien común y de intereses colectivos que abran las puertas a una intensificación de las relaciones a escala global (Palop, 2003).

El avance tecnológico y científico que se ha venido presentado en la sociedad actual ha agudizado el deterioro ambiental, el hombre en sus actividades diarias, muchas de estas realizadas de forma irracional, genera repercusiones negativas que afectan de forma directa la calidad de vida de las personas. Por tal razón, y a raíz de la Conferencia de Estocolmo en 1972, sobre el Medio Humano, se ha venido incorporando en los ordenamientos jurídicos lo relacionado con los derechos ambientales y los mecanismos para su protección efectiva (Pureza, 2004); muestra de lo cual es que tanto el Protocolo de San Salvador, adicional a la Convención Americana Sobre Derechos Humanos en Materia de Derechos Económicos, Sociales y Culturales, en su artículo 11, numeral 1 como la Constitución Política colombiana en su artículo 79 (Legis, 2015 ) consagran el derecho a un ambiente sano.

Esta realidad sobre el agotamiento de los recursos naturales, esgrime una necesidad urgente, relevante y coherente de cuidarlo; visión ésta, que en el ámbito jurídico, obligatoriamente pasa por el concepto jurídico de propiedad, apuntando, las primeras declaraciones de derechos, en la protección al derecho de propiedad (Altamirano, 2003). En tal sentido obsérvese que la Declaración de Derechos de Virginia (1776) expresa en su artículo 1 que: 
todos los hombres son por naturaleza igualmente libres e independientes y tienen ciertos derechos innatos, de los cuales, cuando entran en un estado de sociedad, no pueden privar o desposeer a su posteridad por ningún pacto, a saber: el goce de la vida y la libertad, con los medios de adquirir y poseer la propiedad y de buscar y obtener la felicidad.

Así mismo, la Declaración de los Derechos del Hombre y del Ciudadano (1789), artículo 2 establece que "la finalidad de toda asociación política es la conservación de los derechos naturales e imprescriptibles del hombre. Estos derechos son la libertad, la propiedad, la seguridad y la resistencia a la opresión" (Rabbi, 1996). Entonces, la finalidad de la ciencia, en lo jurídico, para el logro del desarrollo económico está basada en el derecho de propiedad, que tiene como fin último la búsqueda constante del bienestar; la felicidad del ser humano.

El hecho de ser considerado el ecosistema como un todo unitario, es imprescindible la vinculación del principio fundamental de solidaridad contemplados dentro de la protección del ambiente, circunstancia que implica una cooperación no solo interpersonal-vecinal, sino también regional-mundial. La defensa del ecosistema implica la defensa de un bien común internacional, dado que su protección sólo puede alcanzarse y garantizarse en el seno de la comunidad internacional (Rabbi, 1996).

\subsection{Importancia constitucional del derecho al ambiente salo}

Según Altamirano (2003), desde el punto de vista constitucional se puede observar que algunos países incorporan en sus constituciones normas explícitas protectoras del ambiente, como es el caso de la Constitución española que en su artículo 45, numeral 1, establece que:

Todos tienen el derecho a disfrutar de un medio ambiente adecuado para el desarrollo de la persona, así como el deber de conservarlo"; la mexicana artículo 4, párrafo 5, "Toda persona tiene derecho a un medio ambiente sano para su desarrollo y bienestar.

Y la constitución portuguesa en su artículo 66, numeral 1, establece que "Todos tienen derecho a un medio ambiente humano, salubre y ecológicamente equilibrado y el deber de defenderlo.", entre otras; mientras que otros, por el contrario, no lo hacen, sin que ello signifique un desinterés por la defensa del ambiente, lo amparan a través de figuras menos 
directas, ancladas en garantías innominadas de cuya interpretación resulta que se llega al mismo objetivo.

Esta tendencia sobre lo explícito de la protección ambiental no es uniforme, dado que algunos países no lo prevén de esta manera, tal es el caso de Alemania, país que su Constitución no prevé abiertamente la protección al medio ambiente, sino de manera implícita, a pesar de ser uno de los Estados que imprimen particular celo en esta tutela. Al respecto Rabbi (1996), sostiene que el motivo de tal omisión reside en que la población tendría un elevado nivel de expectativa al que realmente podría brindarse.

Después de la Declaración de Estocolmo (1972), varias naciones incorporaron en sus textos constitucionales el derecho a un ambiente sano, ya como un derecho fundamental o como un derecho colectivo de naturaleza social. Dicha consagración permite, tanto al poder ejecutivo como a los jueces colmar lagunas y promover su expansión ante nuevas o crónicas situaciones. En ese sentido, el crecimiento y las crisis de la economía de gran escala industrial y la expansión del conocimiento sobre la naturaleza y la cultura ha favorecido el incremento de técnicas, medios, vías e instrumentos gubernativos, administrativos y judiciales de protección del Derecho al medio ambiente sano (Sentencia C-495 de 1996, Corte Constitucional).

En Colombia, en relación con la problemática acerca de la aproximación entre el derecho fundamental a un ambiente sano y el derecho constitucional a la libertad, existe discrepancia notable al momento en que algunos dan mayor relevancia a la conservación de los recursos naturales, mientras que otros se enfocan exclusivamente en el crecimiento económico (Saavedra, 2014); mientras que Saura (2007) indica que existe un vínculo entre el ambiente y el derecho a la vida, o la intimidad y el ambiente, o la integridad personal y el ambiente, siendo posible apreciar la amplia aceptación existencial sobre la concepción de que para garantizar adecuadamente los derechos humanos se debe proteger el ambiente.

La Constitución de 1991, consagra el derecho de todas las personas al disfrute de un ambiente sano de manera explícita en el artículo 79 bajo el título de los Derechos Colectivos y del Ambiente, el cual establece: 
Todas las personas tienen derecho a gozar de un ambiente sano. La ley garantizará la participación de la comunidad en las decisiones que puedan afectarlo. Es deber del Estado proteger la diversidad e integridad del ambiente, conservar las áreas de especial importancia ecológica y fomentar la educación para el logro de estos fines (Legis, 2016, p. 28).

Este artículo 79 superior, también conocido como derecho a la conservación y disfrute de un medio ambiente sano y a la promoción y preservación de la calidad de la vida, así como a la protección de los bienes, riquezas y recursos ecológicos y naturales; ha sido objeto de grandes reflexiones y preocupaciones que han hecho aparición en el Derecho Constitucional y en el Derecho Internacional (Sentencia C-495 de 1996, Corte Constitucional). Esta misma corporación, sostiene que la protección del ambiente, es un asunto que le compete, en primer lugar, al Estado aunque para ello deba contar con la participación ciudadana, a través del cumplimiento de los deberes constitucionales, en particular, los previstos en el artículo $8^{\circ}$ superior, el cual consagra: "proteger las riquezas culturales y naturales de la Nación", así como el numeral $8^{\circ}$ del artículo 95 constitucional que prescribe entre los deberes de las personas y de los ciudadanos: "velar por la conservación de un ambiente sano".

Entonces, el Estado deberá favorecer la protección de los bienes comunes, pues está en la obligación de propiciar normas que contengan los presupuestos mínimos de protección a los entes territoriales; mientras que éstos últimos deben promulgar reglas que complementen esta iniciativa, sin que dichas reglas alteren las jurisdicciones locales.

\section{EL DESARROLLO ECONÓMICO FRENTE AL MEDIO AMBIENTE}

De acuerdo con Altamirano (2003), en la literatura jurídica relacionada con los problemas ambientales predominan los enfoques desde la perspectiva del castigo o sanción contra la industria que, en su producción, provoca secuelas contaminantes del medio ambiente. Pareciera que existe un desmedido interés en responsabilizar por el ejercicio lícito de una actividad industrial, más que en hallar soluciones razonables y eficaces para favorecer la armonía entre el medio ambiente y desarrollo económico. De acuerdo con Concha-Prada (2017), existe una visión general sobre la minería de estar siempre relacionada con la ilegalidad, y se debe entender que no siempre se llama minería a lo que es minería. Considera que existen formas responsables para manejar el sector como lo viene haciendo 
Estados Unidos e Italia, donde la explotación de petróleo se vincula con la actividad agrícola y ganadera, demostrando que si es posible hacer otro tipo de actividad extractiva.

Desde una perspectiva económica, la regulación ambiental surge de la necesidad de cubrir las divergencias entre costos sociales y privados en las decisiones de producción y consumo; siendo necesario, para el logro de esos objetivos, la mayor eficiencia de los instrumentos económicos -tales como impuestos correctivos-, dado su poder para encauzar el interés privado en favor de los intereses públicos, minimizando el costo total para la sociedad (Quadri de la Torre, 1997).

Actualmente, en la ejecución de la mayoría de los proyectos industriales, casi siempre y en diversos grados se generan efectos que alteran el ecosistema, representando un costo adicional para el proceso industrial que se internaliza. En Norgaad (2002) se califica el actual fenómeno ambiental como una crisis evolutiva que se ha venido materializando durante décadas a partir de la conciencia y denuncia pública del fracaso del modelo inadecuado de extracción, explotación, apropiación, producción y uso de recursos, indicando que nos encontramos en un periodo de insostenibilidad. Altamirano (2003), sostiene que este es un problema complejo y difícil de solucionar, toda vez que podría ser tan perjudicial mantener invariablemente el fenómeno contaminante como erradicarlo totalmente. Además no todo proceso industrial que genera contaminación lo hace en niveles intolerables, pues algunos de estos efectos son subsanados por la propia naturaleza.

Será necesario trazar políticas ambientales razonables inclinadas a la defensa de los recursos naturales, sin que éstas frenen el desarrollo industrial que en gran medida, tiene como finalidad el mejoramiento de la calidad de vida, para ello se requiere, obligatoriamente, la participación estatal. Al respecto, Altamirano (2003) sostiene que aflora así un problema de política económica cuya solución deberá enlazarse con un criterio de contaminación llevado a niveles aceptables y cuidando de no hacer inoperable el sistema económico. Es a partir de la interacción Estado-sociedad, en sus múltiples formas, que pensamos y analizamos el potencial transformador de la política ambiental y las políticas públicas en general. Toda política pública conlleva la potencialidad de un cambio social; es decir, una relación de causa-efecto contenida en las disposiciones que rigen y fundamentan la acción pública (Blanco-Wells et al., 2017). Concha-Prada (2017) asegura que el conflicto 
ambiental surge porque a diferencia de la mayoría de los sectores productivos, la explotación debe hacerse en los territorios donde están los recursos, y éstos territorios por lo general son víctimas del abandono y el olvido del Estado, donde no hay servicios básicos, ni infraestructura, ni condiciones de vida digna, y que por lo general están atravesados por el conflicto armado. Entonces, el objetivo consistirá en encontrar un sistema que pueda lograr un punto de equilibrio en el cual los recursos se confronten con los usos conflictivos, proporcionando los incentivos apropiados para producir resultados flexibles y asimismo que permitan trabajar a un gran número de empresas (Rabbi, 1996).

En este contexto es preciso traer a colación el principio 11 de la Cumbre de Río de Janeiro, el cual establece que:

Los Estados deberán promulgar leyes eficaces sobre el medio ambiente. Las normas ambientales, y los objetivos y prioridades en materia de ordenación del medio ambiente, deberían reflejar el contexto ambiental y de desarrollo al que se aplican. Las normas aplicadas por algunos países pueden resultar inadecuadas y representar un costo social y económico injustificado para otros países, en particular los países en desarrollo." Así mismo, el principio 12 establece que "Los Estados deberían cooperar para promover un sistema económico internacional favorable y abierto que llevara al crecimiento económico y al desarrollo sostenible de todos los países, a fin de abordar en mejor forma los problemas de la degradación ambiental (https://redjusticiaambientalcolombia.files.wordpress.com/2012/09/declaracic3b3n-derio-1992.pdf).

\section{Referencias}

Altamirano, A. C. (2003). El derecho constitucional a un ambiente sano, derechos humanos y su vinculación con el derecho tributario. Derecho \& Sociedad, (22), 314-346.

http://revistas.pucp.edu.pe/index.php/derechoysociedad/article/viewFile/16789/1710 $\underline{2}$

Blanco-Wells, Gustavo., Günther, Ma.G., Gutiérrez, RA., Valencia-Hernández, R. (2017). Introducción. Cambio ambiental global y políticas ambientales en América Latina. Günther, Ma.G., Gutiérrez, Ricardo A. (Coordinadores). En: La Política del Ambiente en América Latina. Una aproximación desde el cambio ambiental global ( $1^{\circ}$ edición). Universidad Autónoma Metropolitana, Xochimilco (México). p. 280. 
Acceso:

04/07/2017. http://biblioteca.clacso.edu.ar/clacso/se/20170612053229/LaPoliticaDelAmbiente.p $\underline{\mathrm{df}}$

Concha-Prada, Jaime. (2017). Conflictos ambientales desde el punto de vista de los empresarios. En: Memorias del lanzamiento del Observatorio de Conflictos Ambientales -OCA. Instituto de Estudios Ambientales -IDEA. Acceso: 04/07/2017. http://oca.unal.edu.co/docs/mem_lanz_oca/Memorias_LanzamientoOCA.pdf

Constitución Política de Colombia. (2015). Edición especial preparada por la Corte Constitucional. Consejo Superior de la Judicatura, Sala Administrativa, p. 125.

Conferencia de las Naciones Unidas sobre Medio Ambiente y Desarrollo Sostenible, Río de Janeiro, junio de 1992. Principios $N^{\circ} 11$ y 12.

Ferrajoli, Luigi. (2001). Los fundamentos de los derechos fundamentales, Trotta, Madrid.

FINNIS, John. (2000). Ley natural y derechos naturales, Traducción de Cristóbal Orrego Sánchez, Abeledo-Perrot, Buenos Aires, p. 228.

Jaume, V., y Jaria, J. (2016). El derecho a un medio ambiente sano: su reconocimiento en el constitucionalismo comparado y en el derecho internacional. Obtenido de DIALNET (Universidad Roviria i Virgilia).

Jiménez Campo, Javier. (1999). Derechos fundamentales. Concepto y garantías. Trotta, Madrid.

Hervada, Javier. (1986). Problemas que una nota esencial de los derechos humanos plantea a la filosofía del derecho. En Escritos de Derecho natural EUNSA, Pamplona. p. 427.

Hervada, Javier. (1990). Introducción crítica al derecho natural. Eunsa, Pamplona, $6^{\text {a }}$ edición, p. 66.

Ibáñez Langlois, José Miguel. (1988). Doctrina Social de la Iglesia, Ediciones Universidad Católica de Chile. p. 205.

Lobo Torres, Ricardo. (1999). Teoria dos Direitos Fundamentais. Editora Renovar. p. 448. 
Londoño Toro, B. (2006). Algunas reflexiones sobre la exigibilidad de los derechos colectivos y del ambiente. En B. Londoño, G. Amparo y G. Herrera (editores académicos). Perspectivas del derecho ambiental Colombiano. p. 622.

Mesa, C. (2008). Derechos de los pueblos indígenas. Ponencia presentada en la Cátedra Jorge Eliécer Gaitán sobre Derechos de los pueblos indígenas. Octubre 8 de 2008.

Moura, F. E. (2014). Los derechos económicos, sociales y culturales como fundamento de la dignidad e igualdad humana. Revista Opinião Jurídica (Fortaleza), 12(16), 165.

Norgaard, R. (2002). Una sicología del medio ambiente coevolucionista. En C. Maria, E. Duque, y P. Herrera. Sicología del medio ambiente: una perspectiva internacional. Madrid: McGraw. Hill. p. 167-178.

Palop, M. E. R. (2003). ¿Nuevos derechos a debate?: Razones para no resistir. Anuario de Filosofía del Derecho, (20), 227-254.

Pureza, J. M. (2004). La protección internacional de los derechos humanos en los albores del siglo XXI. Universidad de Deusto.

Quadri de la Torre, G. (1997). Teoría y práctica en política ambiental y uso de instrumentos económicos. En: Economía Ambiental: Lecciones de América Latina ( $1^{\circ}$ edición). Instituto Nacional de Ecología. Tlacopac, México, D.F. p. 347. Acceso: 03/07/2017. http://www.economia.unam.mx/temarios/94.pdf\#page=36.

Rabbi Baldi Cabanillas, Renato. (1996). Notas para una fundamentación del Derecho ambiental. Revista O Direito, Año 128, I-II. Lisboa. p. 67-68.

Saavedra Forero, Y. P. (2014). El derecho a un ambiente sano y la libertad económica en Colombia: Un estudio sobre los efectos por el conflicto de estos derechos.

Sánchez, L. (2012). El derecho al ambiente sano: esquemas de reconocimiento constitucional y mecanismo judiciales de protección en el derecho comparado. Bogotá: Universidad Nacional de Colombia.

Saura Estapa, J. (2007). El concepto y fundamentación de los derechos humanos emergentes. En G. Ramírez, Los derechos humanos en las sociedades contemporáneas: Diálogos Fórum Universal de las culturas. Monterrey: Fondo Editorial de Nuevo León. p. 71-89.

Sentencia T-092 de 1993. Corte Constitucional. Magistrado Ponente: Dr. Simón Rodríguez Rodríguez. 
EDUARDO ARTURO KERGUELÉN DURANGO

Artículo de reflexión

Sentencia C-495 de 1996. Corte Constitucional. Magistrado Ponente: Dr. Fabio Morón Díaz. 